Commentary

\title{
Forging Smarter Cities through CrowdLaw
}

\author{
Beth Simone Noveck
}

The GovLab, Tandon School of Engineering, New York University, Brooklyn, NY 11201, USA; E-Mail: noveck@thegovlab.org

Submitted: 30 June 2018 | Accepted: 14 September 2018 | Published: 21 December 2018

\begin{abstract}
Public officials are often ill-equipped when it comes to knowing how to regulate complex societal challenges, especially those that involve cutting-edge scientific and technological advances that raise myriad ethical, moral, political, legal, regulatory and social questions. But what if technology could be used to improve the quality of regulation and legislation? Online, tech-enabled participation methods, known as "CrowdLaw", enable more individuals, not only interest groups, to inform the legislative and policymaking processes. In this brief commentary, I survey a handful of global examples which show CrowdLaw in use at each stage of the lawmaking process at the local level and exhibit how participation is improving outcomes.
\end{abstract}

\section{Keywords}

citizen engagement; citizen participation; CrowdLaw; decision-making; policymaking; smart cities

\section{Issue}

This commentary is part of the issue, "E-Government and Smart Cities: Theoretical Reflections and Case Studies", edited by Peter Mechant (Ghent University, Belgium) and Nils Walravens (Vrije Universiteit Brussel, Belgium).

(C) 2018 by the author; licensee Cogitatio (Lisbon, Portugal). This article is licensed under a Creative Commons Attribution 4.0 International License (CC BY).

\section{Introduction ${ }^{1}$}

Communities are grappling with how to regulate new technologies but also with how to stand up to the innovative, yet powerful, private companies that created them. However, public officials are often ill-equipped to negotiate these deals, especially when they involve complex and challenging scientific advances, such as autonomous vehicles, Artificial Intelligence (AI), CRISPR gene editing, or sensor networks. These technological and scientific advances raise myriad ethical, moral, political, legal, regulatory and social questions (Cassani-Davis, 2015).

These questions can include:

- Is current policymaking a legitimate and effective way to make decisions about these technologies?

- Is it even legally acceptable to cede so much power to private interests?

- Is there a way to measure the quality and effectiveness of our legislation and policy?

As we shall explore, the demand on cities to legislate and regulate complex issues effectively-made all the more difficult and urgent because of the still-evolving nature of new technologies - is precipitating the need for bringing greater collective intelligence to bear to enhance the lawmaking processes.

What if new technology could unlock better approaches to lawmaking that would enable more individuals, not only interest groups, to weigh in, not simply on how to advance stakeholder interest, but also on how to solve our collective problems? What if the technologies of collective intelligence could prevent us from being subjugated by technological systems that we cannot understand and that few of us can control. We need platforms to connect public officials and institutions to robust sources of public wisdom in order to help improve policymakers' understanding of science and technology (Susskind, 2018).

New participatory law and policymaking platformswhat I call "CrowdLaw" - leverage technology to tap into diverse opinions and expertise at each stage of the policymaking process to improve the quality of outcomes (Noveck \& Capone, 2017).

Although the name is new, the concept of public engagement, of course, is not. But new terminology is war-

\footnotetext{
${ }^{1}$ This article is based on a longer publication: Crowdlaw: Collective intelligence and lawmaking (Noveck, 2018).
} 
ranted to describe the burgeoning movement in institutionalized practices-as distinct from purely deliberative civil society mechanisms - for using collective intelligence to govern. (Alsina \& Marti, 2018; Noveck, 2018). CrowdLaw differs markedly in quantity and quality from earlier forms of public participation for a variety of reasons. First, CrowdLaw is institutionalized and connected to formal decisionmaking, how money is spent, and how power is wielded. Second, CrowdLaw focuses on obtaining expertise and ideas instead of only opinions. It is not merely a form of better polling or a way to win supporters for political causes, but it is designed to use collective intelligence to solve complex and difficult problems. As such, it goes beyond direct democratic approaches to blend more deliberative and thoughtful mechanisms for making policy. Third, CrowdLaw emphasizes the institutional design needed for individuals to participate and the design needed to digest this distributed knowledge. The focus is not simply on the platform but on the whole institutional process for gathering and using information and translating that raw data into insights for law and policymaking.

\section{Five Stages of Policymaking}

CrowdLaw experiments are taking place at every stage of the law and policymaking process with differing levels of success. Each stage has different informational needs that could be met by an organized use of collective intelligence. We examine an example of CrowdLaw at each of five stages of lawmaking. The stages are, of course, ideal types that in reality sometimes blend together. Nonetheless, distinguishing between them illustrates the need for a careful design of a CrowdLaw process in order to accomplish normative goals.

\subsection{Problem Identification: vTaiwan (Taiwan)}

The vTaiwan experimental e-consultation platform created and led by Taiwanese Digital Minister Audrey Tang enables the broader public to participate in an ongoing process of problem identification. vTaiwan is a multistep, multi-platform method which enables people to flesh out and define a problem posed by the government using an online forum.

The participants collaboratively compose an open, online glossary to ensure that the relevant terms are properly defined. If the definition of the problem is agreed upon by participants, they then proceed with the "discovery" session. They use this meeting to discover any important issues that both sides have. After this, the self-selected group moves to discuss solutions. The vTaiwan method utilizes Pol.is, a machine-learning software that sorts and clusters responses into categories for more efficient review and discussion. This brings attention to the most popular ideas but also allows for the formation of working groups who turn the findings into policy recommendations that are then delivered to the ad- ministration. In more than $80 \%$ of cases, the issues which have been defined by the public have been met with government interest and action. This is largely because the process involves civil servants, lawmakers, citizens and stakeholders in the conversation from the beginning. As the creators explain, the process they follow is designed to lead to "coherence, not necessarily consensus".

So far, 26 national issues, including the regulation of telemedicine, online education, telework, company law and Uber, have been discussed with over 200,000 people participating. Although small and still not the norm, it is a very promising approach, largely because of Tang's leadership in both the civic technology community from which she came and the government which she now serves. Tang has been able to establish a connection between public participation and power.

\subsection{Solution Identification: Better Reykjavik (Iceland)}

In Reykjavik, Iceland, following the banking crisis of 2008, public trust in institutions plummeted. Despite having the oldest parliament in the world and a stable, highfunctioning democracy, people's faith in their political leadership faltered.

Active citizens built an open source platform and process known as Better Reykjavik, an open forum web platform for "idea generation" and "policy crowdsourcing". It gave citizens a forum to present and discuss ideas related to the services and operations of the city of Reykjavik. The website is a simple ideation platform where citizens can post their ideas on relevant topics such as education, transportation, tourism and welfare. They can rate one another's ideas and debate amongst each other in the comment sections. This website has been used by $20 \%$ of Iceland's population and over half of the people registered use it regularly, along with 1.5 million people in 20 countries who use copycat versions of the platform.

A "pros and cons" feature promotes well-reasoned arguments among users of the site by encouraging them to sort and organize their own feedback. This results in a compilation of the best arguments for and against each of the ideas along with a list of solutions. The true novelty is not the technology, but the process which requires that the city try to implement the public's best ideas. Each month, the five highest rated ideas are processed by the appropriate government standing committee. This has led to the implementation of hundreds of ideas from citizens.

The Icelandic case demonstrates the practical example of collaborative decision-making between state and citizens to solve problems, highlighting the ways in which the public can inform the policymaking process with new, innovative and more creative thinking (Olafsson, 2016). It is worth, however, reflecting on how the process and platform could be improved through more careful distinction between defining problems and finding solutions. In addition to this, a better empirical understanding of the institutional impact would be greatly beneficial. 


\subsection{Drafting: Marco Civil (Brazil)}

The process of drafting legislation, which offers instructions to the implementing agencies and to the public, involves turning a policy proposal into a document with legal validity. This is typically done behind closed doors with professional staff assisting politicians to ensure correct formatting, indexing and referencing back to earlier legislation. Participating in this stage is challenging because it demands a high level of commitment and a greater knowledge of the subject matter. There are two ways to make participation in this stage easier. Either participants must have a good understanding of the legal requirements of the process or administrators need to first create a draft without technical jargon and use this to work out the details with non-experts. It can be said that collaboration during this phase could be seen as an invasion of the inner sanctum of the politician's preserve and threatens the essence of representative democracy. When politicians are able to overcome that fear, however, it creates an opportunity for truly open and inclusive lawmaking.

For example, in 2009, the Ministry of Justice in Brazil collaborated with a local law school to launch an interactive website where they posted the first draft of the Marco Civil-a new bill on Internet freedom-for public comments (Souza, Viola, \& Lemos, 2017). This website allowed individual citizens and organizationsincluding NGOs, businesses, and political parties - to add to the law's content. More than 800 contributions were received in the form of comments, e-mails, alternative drafts and references. After three more collaborative drafting phases, the bill was sent to Congress in 2011 and then-President Dilma Rousseff ratified the bill with the support of four ministries.

Although France and the Philippines both followed Brazil's lead, examples of public participation in writing legislation are still few and far between. A handful of pilot projects have been largely successful but there is still a need for more experimentation to determine:

- What is the impact of an extended versus a shortened drafting process?

- What happens when legislative staff participates actively with the public as opposed to leaving citizens and civil societies to draft on their own?

- Given its technical nature, does involving the public in drafting actually pay off in terms of improving the legitimacy or the effectiveness of the process?

\subsection{Implementation: MindLab (Denmark)}

After the legislation is drafted and passed, it still has to be implemented. This is normally the responsibility of the agency to which the legislation has been delegated. Implementation provides another opportunity to practice many of the same techniques already outlined as well as to engage with the public in developing concrete strate- gies to apply. For the last 16 years in Denmark, Mindlab, a cross-ministry innovation lab, facilitated the active involvement of Danish citizens and businesses in developing new public-sector solutions. That is, public servants from Danish ministries brought policy challenges to MindLab for citizens and business stakeholders to collectively participate in the decision-making process, the development of prototypes and large-scale experiments along with the ministries.

MindLab's work focused on human centered design and used iterative design methods such as user journeys, expert interviews, what-if scenarios, and prioritization grids to manage the engagement process. Insights were gathered from their experiments and prototypes in order to determine how initiatives would be implemented by the Danish ministries (MindLab, 2018). In doing so, MindLab directly involved the public in the creation and testing of actual services, policies and programs. MindLab, however, did not use big data or agile new technology in its work. For this and other political reasons, it was disbanded in spring 2018 and incorporated into a new initiative focused on digital and tech-based innovation. Nonetheless, it illustrated the value of involving the public in the implementation process as their experience can aid in producing more detailed and precise plans.

\subsection{Evaluation: Social Auditing in Ghana-TransGov}

Sadly, policymaking and legislation often end with enactment. There is no systematic effort to understand the impact a law had or whom it impacted. Evaluation plays an important role as it provides feedback which can be used to improve existing service delivery and inform future policy formulation. This stage of the lawmaking process is the one most in need of CrowdLaw projects.

TransGov is a platform created in 2014 to help Ghanaian citizens monitor the progress of local development projects by empowering citizens to hold their government accountable for faulty or incomplete infrastructure projects and service delivery in their localities.

TransGov curates a list of projects in local communities and gives people the ability to comment on them. Today TransGov has 600,000 registered users who provide feedback through the TransGov website, mobile app, by SMS or using Interactive Voice Response (IVRS). Although not strictly legislative in nature, it is an instructive example of giving citizens power and using their collective intelligence to monitor policy outcomes thereby creating an evaluative feedback mechanism. Social auditing and monitoring of this kind that take advantage of the distributed power of citizens to monitor the effectiveness of policies could improve legislative practices if they are systematically implemented as part of the lawmaking process.

With experimentation and testing, CrowdLaw has the potential to go beyond accountability to make public institutions more effective by enabling decision-makers to leverage diverse and innovative solutions to solve prob- 
lems more quickly. CrowdLaw can also help by identifying problems like structural inequality which have long been neglected and are yet to be solved.

\section{Conclusion}

Despite having no special training, city officials are often expected to make decisions about an impossibly wide range of complex issues. It is no wonder that in a 2018 survey, the average level of trust that people in 28 countries have in their governments was only $43 \%$ and far lower in many places (Edelman, 2018).

Making policy and legislation that will protect the public while stimulating innovation and the economy demands more expertise. Even the most capable politicians and public servants do not possess all the expertise needed to understand the root causes of problems and then turn the available information into coherent and effective policy. But what if collective intelligence mechanisms could help? What if to become smarter, our cities could tap into their greatest asset, that is, the intelligence and expertise of both their residents and the global public?

We need to re-imagine the processes by which we make laws and regulations. CrowdLaw brings with it the promise of improving the quality and effectiveness of lawmaking while also strengthening citizenship. The projects in Taiwan and Iceland among others are beginning to take off and demonstrate what is possible.

However, it is not always clear how current practices improve the quality of decision-making. Given that they often combine problem identification with problem solving, jumble drafting with commenting and confuse implementation with evaluation, it can be said that these practices are not as well-designed as they could be. The projects that genuinely improve the quality of lawmaking seem to be those that are designed to meet the specific informational needs for that stage of problem solving. However, empirical testing is required in order to understand whether CrowdLaw practices enhance or degrade the substantive quality of democratic decision-making.

These processes utilize software and can be altered with ease so they are capable of running experiments that can test which features of the platform lead to increased participation by a diverse group of individuals. The software can also measure the impact on lawmakers and the lawmaking process.

For example, one could test whether providing users with a checklist, directions and a set of required fields leads to more implementable and realistic proposals. CrowdLaw practices can be greatly beneficial to public institutions which face public pressure to create more legitimate and effective ways to govern. Therefore, research needs to be done to understand the impact of CrowdLaw on the public, city councils and the strength of our democracy.

\section{Acknowledgments}

Thank you to Vishala Pariag for editorial assistance.

\section{Conflict of Interests}

The author declares no conflict of interests.

\section{References}

Alsina, V., \& Marti, J.-L. (2018). The growing CrowdLaw movement. Analyse und Kritik, 40(2), 337-358.

Cassani-Davis, L. (2015, October 9). Would you pull the trolley switch? Does it matter? The Atlantic. Retrieved from https://www.theatlantic.com/techno logy/archive/2015/10/trolley-problem-history-psycho logy-morality-driverless-cars/409732

Edelman. (2018). 2018 Edelman Trust barometer global report. Retrieved from https://www.edelman.com/ trust-barometer

MindLab. (2018). MindLab methods. MindLab. Retrieved from http://mind-lab.dk/en/methods

Noveck, B. S. (2018). Crowdlaw: Collective intelligence and lawmaking. Analyse \& Kritik, 40(2), 359-380.

Noveck, B. S., \& Capone, G. (2017). CrowdLaw-Online public participation in lawmaking. The GovLab. Retrieved from http://crowd.law

Olafsson, J. (2016). The constituent assembly. A study in failure. In P. Urfalino \& I. Erlingsdóttir (Eds.), Valur Ingimundarson, Iceland's financial crisis: The politics of blame, protest, and reconstruction. London: Routledge.

Souza, A., Viola, M., \& Lemos, R. (Eds.). (2017). Brazil's internet bill of rights: A closer look. Rio de Janeiro: Institute for Technology and Society of Rio de Janeiro. Retrieved from https://itsrio.org/wp-content/up loads/2018/02/v5_com-capa_pages_miolo_BrazilInternet-Bill-of-Rights-A-closer-Look.pdf

Susskind, J. (2018). Future politics: Living together in a world transformed by tech. Oxford: Oxford University Press.

\section{About the Author}

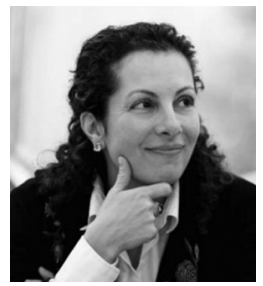

Beth Simone Noveck is a Professor of Technology, Culture, and Society at New York University Tandon School of Engineering where she directs the Governance Lab (GovLab) and its MacArthur Research Network on Opening Governance. Her current research focuses on "people-led innovation", namely the ability of communities and institutions to work together to solve problems more effectively and legitimately. She tweets @bethnoveck. 